\title{
El comercio holandés y la integración de espacios económicos entre Cádiz y el Báltico en tiempos de guerra (1699-1723)
}

\author{
Dutch trade and integration of economic spaces \\ between Cádiz and the Baltic at war times (1699-1723) \\ ANA CRESPO SOLANA \\ Instituto de Historia \\ Consejo Superior de Investigaciones Científicas (CSIC), Madrid
}

\begin{abstract}
RESUMEN
Las relaciones entre política y comercio han influido directa o indirectamente en la evolución de la integración de los mercados y en las rutas marítimas durante la Edad Moderna. Eligiendo una coyuntura bélica de gran trascendencia en el paso del siglo XVII al

XVIII, se pretende realizar un análisis que, desde el punto de vista económico y regional, integre factores histórico-políticos con otros de carácter cuantitativo sobre navegación, con el fin de aproximarnos a las alteraciones originadas por la guerra como factor de desestabilización, especulación y cambio de los intereses creados en torno al mantenimiento de las rutas marítimas que conectaban espacios y regiones. $\mathrm{Al}$ mismo tiempo, se intenta ilustrar cómo los intereses mercantiles lograron evadir

las dificultades en el mantenimiento de la superestructura de las relaciones comerciales. Se ha elegido la ruta entre Amsterdam y Cádiz, eje de vital importancia para el comercio entre el Báltico y el sur de la Península Ibérica.

PALABRAS CLAVE: Comercio del Báltico, Comunidades mercantiles, Países Bajos, España, siglo XVIII Códigos JEL: N10, N13

\section{ABSTRACT}

Relationship between politics and trade has directly or indirectly influenced the evolution of market and maritime route integration in the Modern Age. A highly momentous time of wars between the XVII and the XVIII centuries has been chosen, in an attempt to carry out an analysis, from an economic and regional point of view. Historical and political factors combined with quantification on navigation have been integrated, in order to understand how that provoked a shift in vested interests war, as a destabilising agent and speculation, affected the maritime routes that linked areas and spaces. At the same time, we try to show how mercantile interests overcame the difficulties inherent in maintaining the superstructure of commercial relations. The route between Amsterdam and Cádiz is the chosen example of this, as it was a vital commercial line between the Baltic and the South of the Iberian Peninsula.

KEY WORDS: Baltic trade, Merchant communities, Low Countries, Spain, 18th century

JEL Codes: N10, N13
\end{abstract}




\section{Introducción ${ }^{1}$}

$\mathrm{L}$

as vinculaciones existentes entre política y comercio han sido puestas de relieve para numerosos momentos históricos. La guerra fue siempre un factor influyente en el mantenimiento de las infraestructuras del comercio marítimo; una prolongada situación bélica podía suponer la apertura de nuevas rutas, la creación de nuevos sistemas de organización del transporte e, incluso, un cambio en la estructura del comercio por la introducción de nuevas mercancías en áreas económicas distantes. Ello había sucedido en el Báltico desde la decadencia de la Hansa y se había acentuado después, cuando dicha región estrechó vínculos con las rutas atlánticas y con los puertos del sur de la Península Ibérica y del Mediterráneo. Durante los siglos XVI y XVII, diversos factores externos e internos influyeron y, en cierta medida, determinaron las relaciones económicas entre estas regiones y sus espacios vinculantes. Este estudio se centra en el análisis de cómo impactó el continuo estado de guerra vigente en el tránsito del siglo XVII al XVIII en los intercambios y en el mantenimiento de las rutas marítimas existentes entre el Báltico y el sur de la Península Ibérica, a partir del ejemplo del eje Amsterdam-Cádiz, uno de los más importantes que relacionaban ambos espacios económicos. La coyuntura elegida abarca dos conflictos bélicos de trascendencia, que suponen una brecha de gran relevancia en el cambio de siglo: la Guerra de Sucesión a la corona española (1699-1714) y la denominada Gran Guerra del Norte (1699-1723), que provocó profundas alteraciones políticas en la geografía báltica, en especial la separación de los reinos de Suecia y Noruega. Se trata, además, de un período de crisis general en el que se produjeron cambios dinásticos y territoriales, al tiempo que las casas de comercio luchaban por mantener los negocios mercantiles ya establecidos en las ciudades portuarias claves de las rutas atlánticas. Intentaré explicar cómo era la dinámica de esos negocios entre el puerto holandés y Cádiz. Previamente, haré un resumen de la evolución de los factores que afectaron al transcurrir del comercio del Báltico con el sur de Europa, prestando especial atención al análisis, en ambos extremos de la ruta Amsterdam-Cádiz, de aspectos como el contexto histórico-político, las posibles transformaciones de la estructura del comercio debidas a alteraciones en la demanda y los intereses de los propios agentes comerciales empeñados en el mantenimiento de la ruta.

[Fecha de recepción del original, abril de 2006. Versión definitiva, noviembre de 2006]

Este trabajo es una primera aportación al proyecto "Dynamic Complexity of Cooperation-Based Self Organizing Comercial Networks in the First Global Age" (06-TECT-FP-004) de la Eurpean Science Foundation. Una primera versión se presentó en el VIII Congreso de la Asociación Española de Historia Económica (Santiago de Compostela, 13-16 septiembre 2005). Agradezco a Hilario Casado Alonso y a José Ignacio Martínez Ruiz, así como al resto de colegas con los que tuve ocasión de discutirlo, las interesantes observaciones efectuadas. También agradezco sinceramente sus oportunas ideas para la mejora del texto a los informantes anónimos de Investigaciones de Historia Económica. 


\section{La conexión entre el Báltico y la Península Ibérica: factores inter- nos y externos en su desarrollo histórico-económico}

Durante los siglos XVI y XVII, la articulación de las áreas de comercio estuvo condicionada por la guerra como factor de desestabilización. Ello tuvo consecuencias directas sobre las ciudades portuarias y sus hinterlands, claves en la integración de los espacios marítimos ${ }^{2}$. En cuanto a la relación del Báltico con el sur de la Península Ibérica, el impacto de los conflictos bélicos sobre la evolución de las estrategias espaciales pudo producir, a modo de "efecto dominó", ciertas transformaciones en otras áreas, como la mediterránea, tradicionalmente vinculada a las rutas norte-sur. Desde la Edad Media, las conexiones marítimas entre los puertos hanseáticos y el sur peninsular entroncaban casi siempre con los puertos del Levante. Por otra parte, muchas áreas del norte europeo sólo tenían salida hacia el Atlántico a través de los puertos hanseáticos y neerlandeses; el Mar del Norte y el Canal de La Mancha formaban un espacio relacionado con el Estrecho del Sund. El que a esta zona viertan sus aguas algunos grandes ríos europeos explica, además, que amplias regiones del interior del continente canalizaran hacia ella buena parte de sus tráficos. La apertura atlántica y la decadencia de la Hansa, fenómenos casi coincidentes en el tiempo, abrieron la gran carrera por el comercio del Báltico entre ingleses y holandeses, aunque $\sin$ menospreciar la presencia de otras naciones europeas en esta aguas. ${ }^{3}$

El análisis de la ruta comercial que unía el sur de España con el Báltico es un exponente interesante para comprender los mecanismos de esta integración marítima y espacial. En este marco, el puerto de Cádiz era un punto nodal de conexión con el Mediterráneo y, sobre todo, con América, razón por la cual tanto las firmas del norte de Europa como las compañías de monopolio inglesas, holandesas y suecas deseaban tener acceso a él. Además, la ruta entre Amsterdam y Cádiz era uno de los ejes principales de esta conexión, por el que transitaban, relacionando regiones, mercancías de alta demanda. Comprender este intercambio exige partir de unos antecedentes estructurales. En un clima general de conflictos, la navegación por el Báltico se vio alterada por la creciente presencia de ingleses y holandeses. La situación socioeconómica interna de las economías bálticas, de tinte feudal, provocó que sus economías exteriores dependieran de la injerencia de los navegantes y mercaderes de las provincias neerlandesas, que durante muchos años financiaron las exportaciones desde estas zonas a los centros de redistribución. La descripción clásica de Braudel de cómo las colonias mercantiles asentadas en los puertos bálticos extraían beneficios de las exportaciones de materias primas, sin involucrarse en su producción, 


\section{GRÁFICO 1}

NÚMERO Y NACIONALIDAD DE LOS BARCOS QUE ATRAVESARON EL SUND, 1550-1800

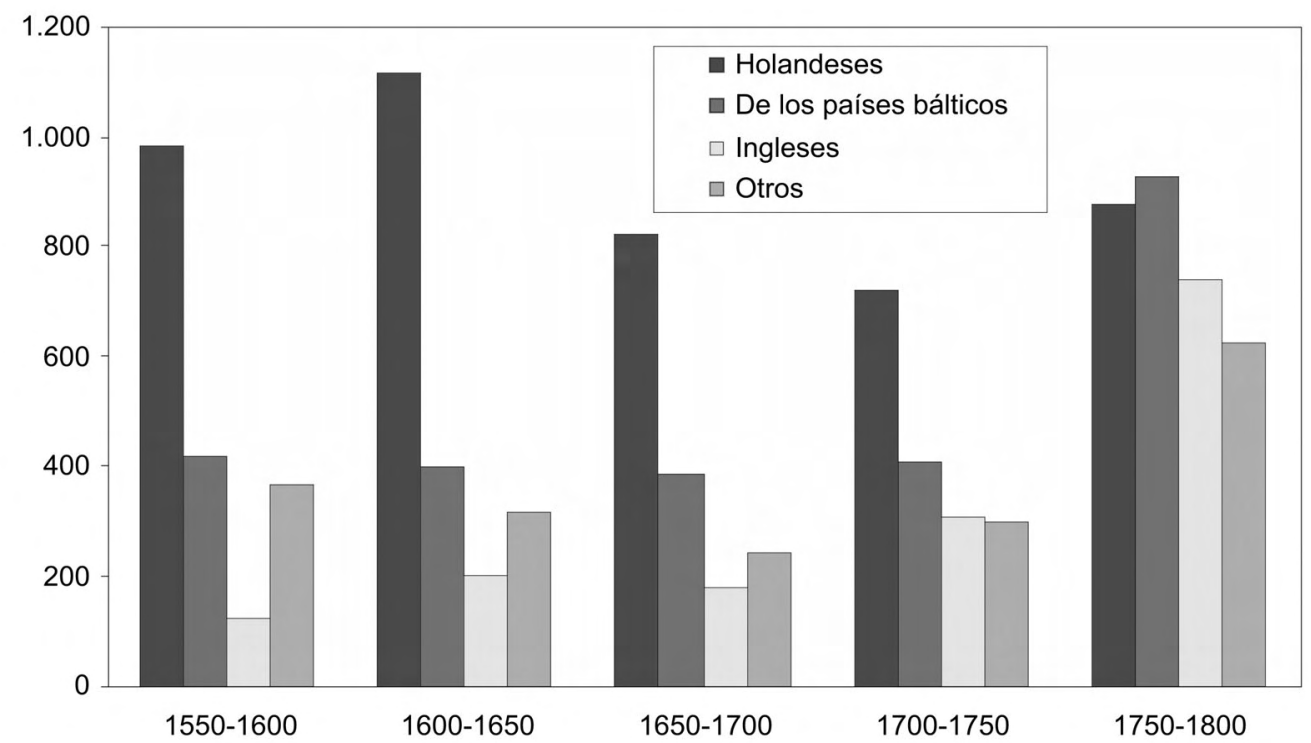

Fuentes: Janzen (1998); Lemmink y Van Koningbrugge (1990); Gemeente Archief Amsterdam (GAA, en adelante) 5050 y 5052.

explica en parte el monopolio del comercio del grano que durante casi tres centurias tuvieron las firmas europeas noroccidentales ${ }^{4}$. El espectacular crecimiento del comercio báltico en el siglo XVII se debió a una variable más: algunas de sus regiones eran abastecedoras de artículos imprescindibles para la construcción naval y de otras riquezas naturales, lo que empujó a naciones expansionistas como Francia, Inglaterra e, incluso, Rusia, a penetrar en sus mercados. Paradójicamente, la continua situación de guerra en los siglos XVII y XVIII obligó a los maritime power a acceder directamente a los recursos naturales escandinavos ${ }^{5}$. Otro elemento de alteración consistió en la introducción de productos coloniales, llevados precisamente por ingleses y holandeses, los cuales incentivaron su demanda a cambio de sustraer grandes cantidades de grano y de materias primas para sus industrias. Las importaciones de textiles también estuvieron aseguradas por la competencia anglo-holandesa, provocando un incremento del movimiento comercial en esta área ${ }^{6}$.

$4 \quad$ Braudel (1974), vol. 3, p. 139.

$5 \quad$ Miller (1987), pp. 167-182.

$6 \quad$ Steensgaard (1990), pp. 103-152; Ormrod (2003), p. 60. 
Para el transporte holandés, la complementariedad entre el Oostzee (el Báltico o mar de Oriente) y el mar de Levantse (de Levante o Mediterráneo) era fundamental, así como la importancia de la escala gaditana. La mayor parte de los viajes de negocios tenían continuidad con los puertos del Levante español, vías de aprovisionamiento de vino, frutas, productos del agro (aceite de oliva, sobre todo) e, incluso, lana española.

De hecho, la travesía del Sund (Sont u Öresund) era casi un espejo de los cambios estructurales acaecidos en la economía europea. Según Faber, y como recoge el Gráfico 1, las flotas holandesas siempre ocuparon, al respecto, un lugar de privilegio. La presencia neerlandesa en este espacio conoció momentos de inflexión, en la segunda mitad del siglo XVII, así como de relativa recuperación que, sin recobrar el esplendor anterior, propició un nuevo "boom" entre las décadas de 1760 y 1780, justo antes de la era napoleónica. En términos absolutos, puede afirmarse que el transporte holandés sólo fue superado a partir de la década de 1740 por el protagonizado por los hanseáticos, en concreto por los convoyes hamburgueses. Pero los holandeses no estuvieron solos en este espacio: los ingleses empezaron a ganar importancia precisamente en la segunda mitad del Seiscientos, en un período de retracción de la expansión holandesa; no obstante, no se sabe hasta qué punto ello sólo fue producto de la decadencia neerlandesa, o bien una simple derivación del incremento espectacular del comercio báltico acaecido en esta época, sobre todo en lo relativo a la demanda de productos coloniales ${ }^{7}$.

El papel del transporte neerlandés en la conexión entre el Báltico y el sur de la Península Ibérica no ha sido aclarado del todo por la historiografía, aunque se cuenta con suficiente información como para hacer posible su descripción y una somera cuantificación. Para el período anterior a 1700, los estudios han hecho hincapié en las causas que pudieron influir en los altibajos experimentados por aquél, subrayando principalmente las intervenciones militares de la Monarquía Hispánica (sobre todo, la serie de embargos entre 1585 y 1648), los frecuentes ataques corsarios con base en Flandes (Dunkerque) y la penetración inglesa en el Báltico en los lapsos de alianza con España. Estas circunstancias dañaron el comercio holandés pero no lo aniquilaron, empleándose en él una media anual de 100 barcos durante la Tregua de los Doce años $^{8}$. Otras cuestiones, como la creación del Almirantazgo de los Países Bajos septentrionales (1624) y ciertas estrategias de la política olivarista, provocaron impactos coyunturalmente negativos. Pese a la crisis detectada por Jonathan Israel a partir de

\footnotetext{
$7 \quad$ Las fuentes más utilizadas han sido los llamados verhoogde last-en veilgeld, o los Paalgeld Poorteboeken (la versión neerlandesa de los Portbooks ingleses); Faber (1989); Jeanin (1964), pp. 55, 102 y 307-340; Steensgaard (1990), p. 113; Federowicz (1980), p 72. Los datos relativos a los Nederlandse Sontregisters están en http://www.nationaalarchief.nl.sont.

$8 \quad$ Israel (1988), pp. 89-105.
} 
1621, y en relación a los puertos españoles, la alternancia observada con los buques hanseáticos hace sospechar de que muchos de los barcos con esta bandera llegados a los puertos andaluces antes de la paz de 1648, fueran en realidad navíos holandeses que cambiaban su pabellón para no ser interceptados por las autoridades españolas. Hay que tener en cuenta, no obstante, que la navegación desde Hamburgo hasta el sur peninsular era ya notable en estas décadas del Seiscientos, aún padeciendo también por las guerras europeas ${ }^{9}$.

En varias ocasiones, España firmó tratados con otras potencias europeas para eludir la incómoda intermediación de sus enemigos. Los acuerdos firmados en 1604 con Inglaterra y Francia, y con la propia Hansa en 1607, o el hispano-danés de 1630 (ratificado en 1632 y 1641) intentaban evitar la participación holandesa en el comercio danés y sueco con España, pero sus cláusulas no fueron respetadas ${ }^{10}$. También otras circunstancias coadyuvaron a la permanencia de los holandeses como mediadores en esta ruta. El acercamiento diplomático con España en los acuerdos de Münster y La Haya reforzó la ruta norte-sur, algo que aprovecharon las casas comerciales neerlandesas para lograr fletes en los que se diseñaba un viaje más largo con la intención de hacer escala en puertos bálticos y mediterráneos como destino último de los convoyes. En concreto, para la ruta Amsterdam-Cádiz, ello se vio reflejado en los acuerdos para sostener la ruta y las oficinas gaditanas de la Sociedad del Comercio de Levante de Amsterdam y Midelburgo a partir de $1630^{11}$. La paz entre Holanda y Suecia, negociada en abril de 1673, supuso un repentino crecimiento de la presencia de buques holandeses en el Sund, en una época en la que la navegación de la República estaba decreciendo en términos generales por las crisis internas y la competencia inglesa. Pronto volvería a menguar de modo considerable, al recrudecerse los conflictos bélicos en Europa a partir de finales de 1690, como puede apreciarse en el perfil de este movimiento marítimo a largo plazo que permite reconstruir los Sund Toll Registers, recogido en el Gráfico $2^{12}$.

La mayor parte de los buques procedía de la provincia de Frisia, seguida de otros puertos del norte como Harlingen, aunque de todos ellos era Amsterdam, quizá, el más importante en lo que a salidas atlánticas se refiere. En realidad, ello se explica por la importancia de la conexión con otras áreas que hacían los fletes contratados en este puerto. Esta abundante navegación se justifica en parte por el

Echevarría (1986), pp. 57-98; Stols (1971), Vol. 1, pp. 14-25; Israel (1988), p. 97; Ellinger (1906-1933); Ijzerman (1931), pp. 163-291; Gómez-Centurión (1988); Johansen (1987), pp. 233-249; y Pietschmann (1998), pp. 1.763-1.796.

Johansen (1987), p. 240.

Crespo (2000); Israel (1990), pp. 133-162; Herrero (2000), pp. 65 y ss.

Biblioteca Nacional, Madrid (BNM, en adelante), Memorial de los Señores Embaxadores Extraordinarios de Su Real Majestad de Suecia, entregado a Sus Altezas los Señores Estados Generales de las Provincias Unidas en 18 de Avril de este año de 1673, La Haya. 


\section{GRÁFICO 2}

NÚMERO DE BUQUES HOLANDESES EN EL SUND, 1497-1783

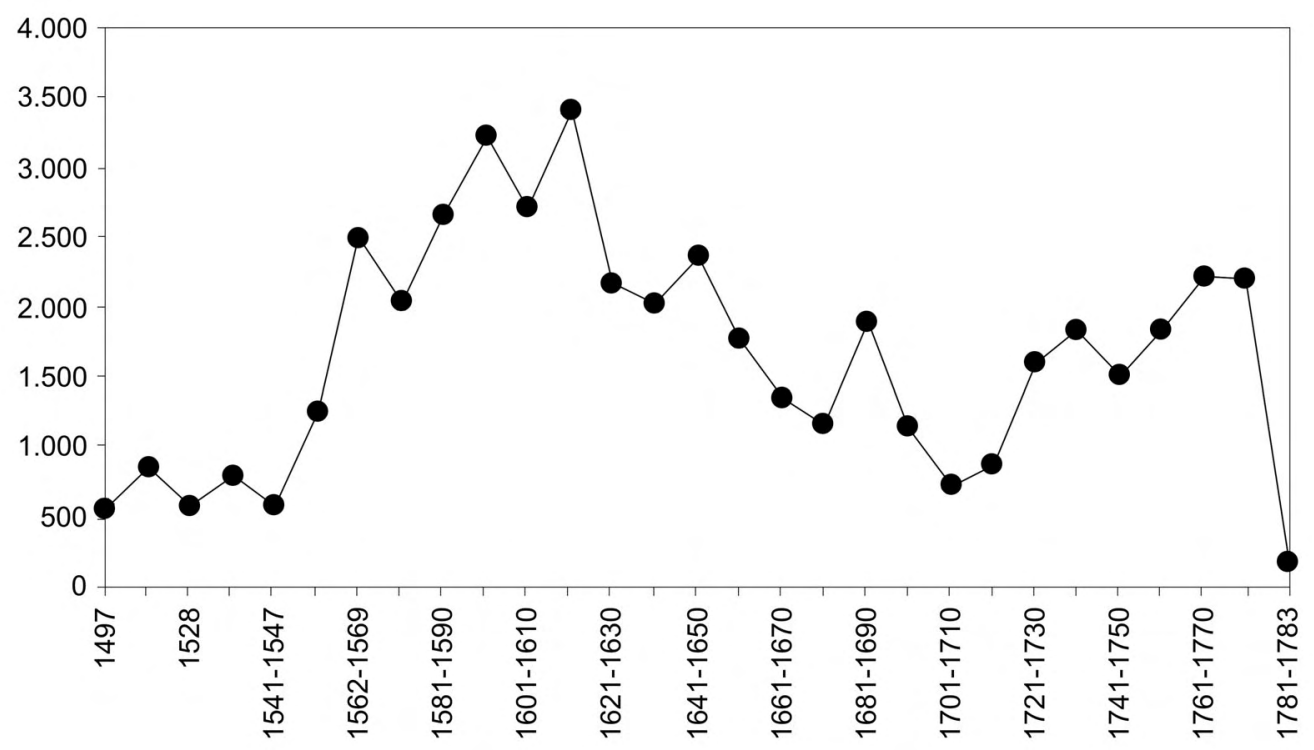

Fuentes: Faber (1988); Jeanin (1964).

monopolio del comercio de grano que los holandeses poseyeron durante amplios períodos, sobre todo del siglo XVII, hasta tal punto que, incluso, se ha detectado una conexión entre dicho comercio y las fluctuaciones económicas de la República, cuando aquél comenzó a decaer en la segunda mitad de dicha centuria ${ }^{13}$. Los peores lapsos coincidieron siempre con épocas de guerra. Por ejemplo, la guerra con Dinamarca de 1541 a 1547 pareció poner en peligro el protagonismo arrebatado a la Hansa. Durante la revuelta holandesa contra el Imperio, entre 1574 y 1580, también se registra un descenso, pero los problemas eran especialmente graves para los convoyes holandeses cuando tales conflictos se superponían a otras guerras paralelas, o casi paralelas, como la de Suecia y Polonia entre 1621 y 1629, que acabó envolviendo a Dinamarca en la Guerra de los Treinta Años con Alemania y con Suecia desde 1631. Con Suecia, en concreto, las relaciones económicas también se habían visto influidas por el sentimiento político conservador que mostraría el reino escandinavo durante la guerra de las siete provincias contra los Habsburgo. A partir de 1679, ambos con- 
tendientes se beneficiarían de una neutralidad mutua que permitió a Holanda seguir comerciando con los puertos suecos durante las guerras de comienzos del siglo XVIII. La fuerte interdependencia económica entre ciertas regiones bálticas y la República se vio reforzada a finales del Seiscientos con el establecimiento de numerosas colonias de mercaderes neerlandeses, como la de Estocolmo; ésta, formada por un grupo de prominentes firmas comerciales, sólo declinaría a mediados del siglo XVIII, coincidiendo con el colapso de la navegación entre Holanda y Suecia ${ }^{14}$.

El Gráfico 3 muestra la irregularidad de la presencia de barcos holandeses en el Sund con destino posterior a Cádiz entre los años inmediatamente anteriores y posteriores a la Guerra de Sucesión española y los conflictos bálticos. Hay que indicar que, aparte del problema sucesorio español, con episodios tan relevantes en el sur peninsular como el asedio a Cádiz en 1702 (al que se añadió el hundimiento de la flota de Nueva España ese mismo año), otros inconvenientes entorpecieron este comercio. La proliferación de las actividades de los piratas suecos y la prohibición por parte de Suecia de todo comercio neutral con sus puertos durante el recrudecimiento del conflicto con Rusia, lo que perduró después de 1713 debido a las intenciones suecas de hacerse con las riendas de sus propias actividades económicas con el exterior, entrañaron que la República perdiera un fácil acceso a diversos puertos del Báltico oriental. Pero, pese a la consiguiente inflexión, la navegación holandesa en el Báltico se recuperaría de inmediato en términos relativos.

Respecto a la competencia inglesa, hay que indicar que los registros del Sund muestran claramente la posición secundaria de las flotas de ese pabellón. En cuestiones puramente comerciales, hay indicios de que Gran Bretaña sólo superó a Holanda en la introducción de textiles en ciertos puertos bálticos, al igual que lo hizo en los puertos andaluces. Los comerciantes ingleses habían conocido una época dorada en la primera mitad del siglo XVII, cuando mantenían relaciones directas con los puertos de Dantzig y Elbing (pertenecientes a la confederación polaca), pero se ha observado su declive a partir de 1620, conforme se operó una fuerte penetración holandesa en esa área comercial. En los años anteriores a 1649, aquéllos fletaron un elevado número de buques con destino a las costas polacas, apreciándose una alternancia entre ambas naciones y registrándose una activa navegación entre puertos bálticos y británicos, especialmente Newcastle, Hull y Londres. Estos indicios plantean la necesidad de conocer más datos para los años comprendidos entre 1667 y 1674, período cumbre en la disminución de obstáculos legales para el comercio de extranjeros en España, teniendo en cuenta que la competencia anglo-holandesa en el Báltico y con los puertos españoles acaeció al mismo tiempo que una serie de alternancias coyunturales en las relaciones de ambas naciones marítimas con la Monar- 


\section{GRÁFICO 3}

NÚMERO DE BUQUES HOLANDESES EN EL SUND CON DESTINO A CÁDIZ, 1680-1730

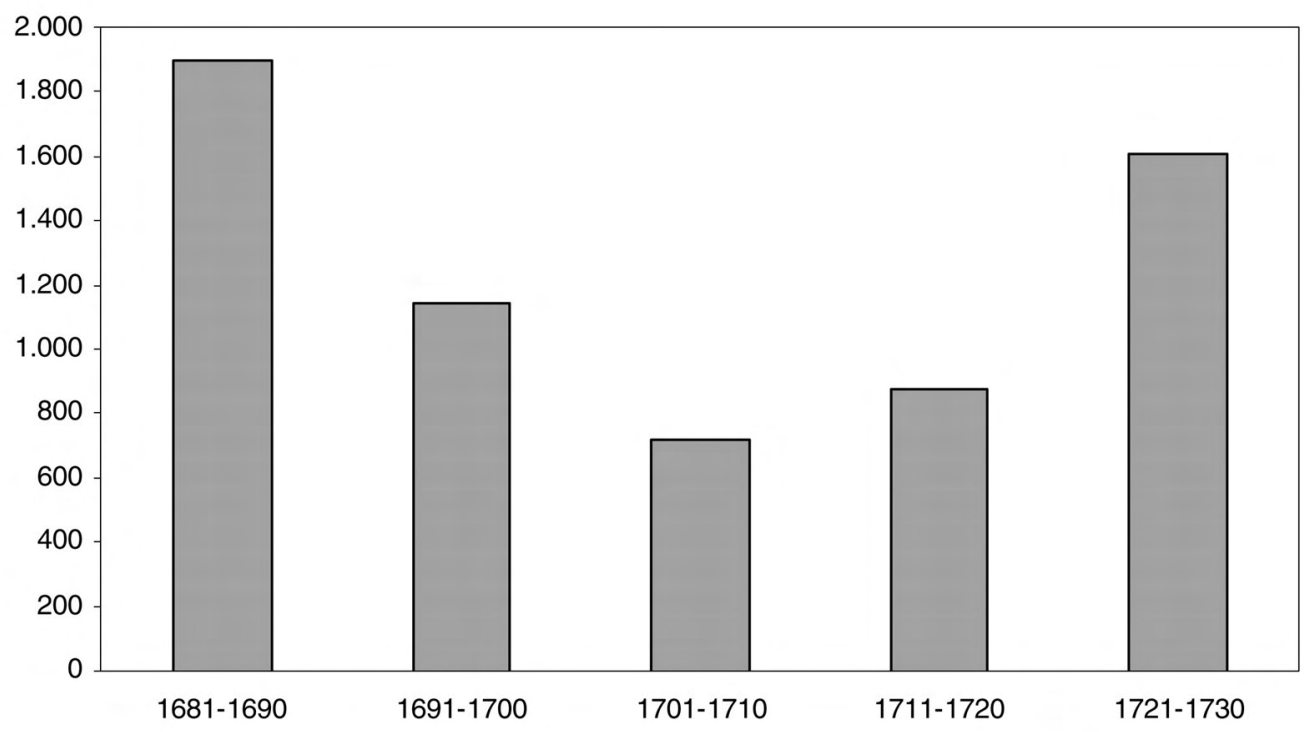

Fuentes: Faber (1988), pp. 19-21; GAA, Notarial Archieven, 3353/991; 3710-I/142; 3350/1316; 5879/1089; 3350/1370; 6903/313; 5287/959-1471-1479-1507; 2287/187-211-236; 5879/543-599-1118; 6903/827; 6561/569; 6562/235; $3351 / 1843-2035 ; 5881 / 983 ; 3352 / 1455 ; 3353 / 2273 ; 5288 / 1203 ; 3729 / 712 ; 2941 / 1613 ; 3729 / 770-772$; 3354/697; 5289/249; 6594/290; 5289/325; 3354/1067; 4988/529; 3355/317; 3356/51-339; 5886/451; 6565/736; 5291/1941; 6567/115; 4200/1257; 4205/445; 4206/425; 7281/11; 7285/275; 6771/759; 6772/23; 5903/1107; 7283/285; 6774/303; 5674/777; 7286/1115; 6413/925; 5909/933; 7287/57-1251; 5910/893; $6613 / 371 ; 6614 / 889 ; 5913 / 923 ; 5116 / 311-318$.

quía Hispánica. Mientras que entre 1630 y 1654 se estrechó la vinculación de Inglaterra con España, a partir de 1654 la República Holandesa se convirtió en el principal aliado político y comercial, situación que se prolongó hasta 1667, si bien Inglaterra conseguiría consolidar su posición a partir de esa fecha y en posteriores tratados, como el de Utrecht, en 1713. Durante los años de la Gran Guerra del Norte, y debido a desentendimientos diplomáticos anglo-polacos, la colonia de mercaderes ingleses en Elbing fue disminuyendo hasta casi desaparecer en $1700^{15}$.

Pero en relación a España se puede afirmar que las incursiones de las flotas inglesas en el Báltico, aunque abundantes, no pueden compararse con el papel que 
desempeñaban los buques holandeses en esta larga navegación de escala entre puertos. Y, aunque la competencia inglesa supuso un notable obstáculo, sobre todo entre 1651 y 1680, por las Actas de Navegación y el desencadenamiento de una serie de guerras en el oeste y norte de Europa, que pusieron en peligro este sistema, la navegación holandesa entre el Báltico y el sur de España se mantuvo y consiguió remontar los notables reveses que sufrió, como puede comprobarse al observar el perfil de este comercio en la larga duración.

También era muy importante, sobre todo para el puerto de Cádiz, la relación con el de Hamburgo. La conexión con este puerto era primordial, si bien sólo a partir de mediados del siglo XVIII los hanseáticos empezaron a demostrar su protagonismo en esta navegación. Una de las razones estaba en el hecho de que los comerciantes establecidos en Hamburgo, entre los cuales se encontraban muchas casas judías y de inmigrantes de otras zonas de Europa, negociaban con productos ultramarinos procedentes de las colonias hispanas, haciéndolo normalmente por vía indirecta desde España y Portugal, a través del tráfico marítimo con Francia e Inglaterra e, incluso, con Dinamarca ${ }^{16}$. No se tienen estadísticas fiables del comercio entre Hamburgo y Cádiz, u otras ciudades españolas, para la época anterior a 1740 que no sea el que se hizo con buques holandeses. Ya desde 1670, el puerto de Hamburgo se convirtió en un área de redistribución de productos coloniales (especialmente azúcar, tabaco, café e índigo), pero también de otros que presumiblemente venían de puertos andaluces en gran parte, como vino, aguardiente, pasas o aceite de oliva. Las importaciones, en su mayoría, consistían en productos de las plantaciones holandesas y de las Indias Orientales. En 1678, según el valor de estas importaciones, eran Gran Bretaña, España y Holanda los principales países abastecedores. Hamburgo, Londres y Amsterdam eran los puertos dominantes en el movimiento comercial y portuario hacia el Báltico y en la conexión con el Mediterráneo a través del sur de la Península Ibérica. En cuanto a los convoyes utilizados, se sabe que fletaban pequeñas flotas de 6 ú 8 paquebotes a otros puertos nórdicos, como Arcángel. Dado el gran crecimiento de su flota mercante durante el siglo XVII, los buques de Hamburgo fueron utilizados en el comercio portugués con Brasil y por algunos comerciantes de Zelanda, concretamente de Midelburgo, en sus transacciones con España ${ }^{17}$. Durante los años de la Guerra de Sucesión española, algunos financieros hamburgueses aportaron dinero en los subsidios de otras ciudades bálticas. Conforme avanzó el siglo XVIII, el comercio de Hamburgo fue ganando un protagonismo creciente en la zona ${ }^{18}$.

\footnotetext{
16 Webber (2004), pp. 37-87; Pietschmann (1992), pp. 455-485; Jeannin (1971), pp. 41-73; Pohl (1963); Johansen (1987), pp. 233-249; Liebel (1965), pp. 207-238.

$17 \quad$ Newman (1985), pp. 57-93 y 86-87.

$18 \quad$ Krawhel (1991), pp. 47-69; Pohl (1963); Webber (1999), pp. 93-126.
} 
Por último, uno de los rasgos estructurales del comercio y la navegación entre Cádiz y Amsterdam en la segunda mitad del siglo XVII fue la paulatina pérdida de importancia, para las flotas norte-europeas, de la conexión mediterránea, debida a las continuas crisis bélicas de la zona y al creciente interés de aquéllas por los mercados americanos cuya puerta de acceso era Cádiz. Hay que decir, no obstante, que una de las principales fuentes sobre el comercio holandés con el Levante, la Directie - o Sociëteit- van de Levantse Handel (Dirección o Sociedad del Comercio de Levante) de Amsterdam y Midelburgo, fue menos estricta en la recopilación de datos sobre las mercancías embarcadas ${ }^{19}$. No existen datos fiables sobre la navegación entre Cádiz y Amsterdam en la segunda mitad del siglo XVII y aún quedan por realizar análisis más amplios dentro de un contexto general. Es posible, sin embargo, hacer algunos comentarios sobre la presencia de buques holandeses en el Estrecho de Gibraltar a finales del Seiscientos gracias a la información recogida en los Straatvaartlijsten (listas del Straatvaart). Según éstas, los convoyes, constituidos por una media de 130 a 150 buques, proseguían, pasado el estrecho, hacia diferentes ciudades mediterráneas, incluidas Esmirna y Alepo. En todo momento, y pese a las sucesivas crisis bélicas de la zona, la República Holandesa quiso mantener el contacto con los puertos de Asia Menor. El escenario político era, sin embargo, muy hostil, tanto por la dura competencia con los transportistas ingleses, como por la continua amenaza berberisca, factores que empezaron a minar dicho comercio en las dos últimas décadas del siglo XVII. Hacia 1690, los mercaderes genoveses eran de nuevo, al parecer, los amos de la navegación entre España e Italia, habiendo aprovechado las rivalidades entre las potencias norte-europeas, aunque sobre esta cuestión sólo hay datos aislados ${ }^{20}$.

\section{El contexto político de comienzos del siglo XVIII}

La Guerra de Sucesión española (1699-1714) y la Gran Guerra del Norte (1699-1723) produjeron diversas alteraciones en la evolución de este comercio. En general, es posible atisbar el afán holandés por evitar que ambos conflictos se relacionaran y lograr así una vía diplomática que salvaguardase su navegación hacia el sur. La diplomacia anglo-holandesa, ahora unida por una causa común (la lucha contra la 
casa de Borbón), se decantó por esta vía, tratando de aislar los intereses de los países bálticos de los del bloque atlántico. Durante las dos guerras iniciadas hacia 1700, la República asistió económicamente a la guerra de Suecia con Dinamarca y se mantuvo al margen del conflicto suscitado tras el asesinato de Carlos XII y la rendición de las provincias bálticas a Rusia. Pero la capitulación de la armada sueca en la campaña rusa, al fallecer el rey, supuso el inicio de un cambio en la constelación de poder en el Báltico y en la Europa nororiental que sí interesaba a las potencias occidentales ${ }^{21}$.

Las alteraciones políticas en el Báltico también afectaron a las relaciones con España y la República Holandesa y, por ende, a la evolución de las rutas comerciales. La gran inestabilidad de los países escandinavos hacía peligrar el acceso a los mercados bálticos, algo que era condición sine qua non para la continuidad de la conexión holandesa con el sur. Las pérdidas de territorios, el deterioro de la hegemonía sueca, sobre todo tras el Tratado de Nystad (1721), y la aparición de Rusia como gran potencia, produjeron cambios de importancia. Suecia perdió Bremen y Verden, que pasaron a la casa de Hannover. El advenimiento de dicha casa al trono de Gran Bretaña incrementó el interés de este país por los problemas del norte de Europa; no en vano, los ingleses extraían de Suecia gran parte de las maderas y los pertrechos que precisaba su creciente flota. Al mismo tiempo, una delicada situación política interna imposibilitó la proyección sueca hacia el exterior durante los primeros cuarenta años del siglo XVIII. Tanto la difícil situación de Suecia, como los intereses holandeses en la labor de mediación entre los diversos bloques de alianzas que se sucedieron por el temor ante una gran ofensiva rusa, dificultaron durante algún tiempo las relaciones con España. El acoso de Rusia a los principales centros de avituallamiento de maderas y trigo (y otros productos que solían embarcarse rumbo a los puertos del sur peninsular) ponía en peligro el comercio holandés en Europa. Aunque el éxito ruso se vio oscurecido en 1711 por la amenaza turca, Rusia volvió a declarar la guerra a Suecia, que contó en esta ocasión con el apoyo de Inglaterra (tras la firma del Tratado de Altona en 1709), interesada ahora en lograr suplantar a los transportistas holandeses en el acceso a los puertos suecos. Empero, aunque Inglaterra necesitaba equipamiento para su industria naval, las compañías suecas rehusaron cargar sus mercancías en buques de ese pabellón por la carestía de los fletes ingleses; este problema no se resolvió hasta 1715 y 1727, cuando Inglaterra volvió a enviar flotas (unas diez) con el objeto de defender sus extracciones de materias primas ${ }^{22}$.

\footnotetext{
21 Nacional Archief, La Haya (NA, en adelante), Archief van de Gezanten en consuls in het buitenland tot 1813. Inventaris Zweden, Pruisen, Polen, Saksen. Gezantes van de Staten Generaal in Zweden in de periode 1674-1806. Van Koningsbrugge (1990), pp. 141-159.

22 Lindblad (1982).
} 
Otro de los peligros que amenazaron temporalmente al comercio entre el Báltico y Cádiz fue el cambio de dinastía en España (al que las potencias bálticas habían mostrado su oposición en años anteriores), que afectó a las relaciones políticas y comerciales de España con las naciones bálticas. Un ejemplo fue el enfriamiento de las relaciones hispano-danesas desde 1702. Empero, Dinamarca no veía a España como una enemiga para sus intereses políticos, por lo que menudearon los esfuerzos para negociar una serie de acuerdos comerciales que facilitasen el intercambio de ciertos productos demandados en las regiones septentrionales y en el Mediterráneo En realidad, el verdadero problema de Dinamarca era Rusia. A Dinamarca afluyeron gran cantidad de capitales y numerosos técnicos extranjeros, entre los que se encontraban muchos holandeses interesados en invertir en el comercio con algunas ciudades españolas, sobre todo en el de pertrechos navales ${ }^{23}$.

En este contexto, otra cuestión afectó a las relaciones comerciales entre España y Holanda. Las relaciones anglo-holandesas pasaron en estos años de una activa cooperación, a tono con la alianza anglo-Orange, a un distanciamiento en los intereses comerciales por razones de competencia en el dominio de ciertas áreas económicas. El punto de fricción se centró principalmente en el Atlántico y en el comercio con las colonias americanas, en el cual los ingleses estarían más interesados a partir de la firma de los tratados con España en 1713. Entre 1701 y 1721, los Almirantazgos de la República enviaron diversos escuadrones al Sund para proteger el comercio holandés que, en ocasiones, fue interceptado debido a la rivalidad con Dinamarca y al apoyo prestado a Suecia. En los primeros años del Setecientos se registró una complicidad anglo-holandesa derivada de la alianza política de dichas naciones y de la necesidad de que, en algunos viajes, los convoyes de ambas escoltaran a los navíos mercantes en sus rutas hacia Dantzig, Riga o San Petersburgo. Por otra parte, los problemas financieros de los Estados Generales, que en ese momento se estaban esforzando en sostener el ejército confederado de Guillermo III de Orange en sus pretensiones dinásticas contra Francia, provocaron la merma de su flota; ésta se vio drásticamente disminuida y solo superaría la crisis a partir de 1713, gracias a las oportunas inversiones de las compañías privadas holandesas ${ }^{24}$.

Al contrario de lo sucedido en la zona atlántica, Gran Bretaña no consiguió desbancar completamente a los holandeses en el comercio con ciertas áreas europeas, y especialmente en la conexión entre el Báltico, el Mar del Norte y el Mediterráneo. A Inglaterra le costó mucho esta competencia y la razón era, en gran medida, su incapacidad para acceder, con verdadero dominio de los mercados, a los amplios circuitos comerciales a los que los holandeses concurrían ${ }^{25}$. Con todo, gracias al buen

\footnotetext{
Alegre (1978), pp. 18 y 29-43.

Bruijn (1970); Lemmink (1990), pp. 161-204 y 200.

Ormrod (2003), p. 60.
} 
hacer de las propias comunidades mercantiles neerlandesas en puertos como Estocolmo o Arcángel y a su intervención en los conflictos bálticos, la República Holandesa consiguió superar la fuerte inflexión que sufrió su conexión entre el Báltico y el sur de la Península Ibérica en los primeros años del siglo XVIII. Además de estos factores de naturaleza política y diplomática principalmente, otra cuestión relevante es la de la crisis del Mediterráneo. Es conocido el interés secundario que tenía el Mediterráneo para las potencias atlánticas, sobre todo a partir de comienzos del Setecientos; sin embargo, ello sólo afectó en cierta medida al comercio gaditano, ya que Cádiz se había convertido, ya en la década de 1670, en el centro de distribución de plata hacia los países mediterráneos. Para el comercio holandés, las vinculaciones atlántica y mediterránea se convirtieron en dos focos de actividad complementaria, si bien éste es un tema aún pendiente de un estudio más detallado.

\section{Amsterdam y Cádiz: dos puertos en tiempos de guerra}

Gracias a las fuentes conservadas es posible ofrecer información sobre la regularidad de la navegación efectuada por los convoyes holandeses entre los puertos bálticos y Cádiz en el contexto bélico de comienzos del siglo. No obstante, las lagunas bibliográficas y los problemas que plantean las fuentes hacen necesario profundizar aún más en temas interrelacionados como, por ejemplo, el estudio del vasto espacio terrestre que estas rutas conectaban. En el caso del Báltico ello es de gran importancia pues, debido al enorme hinterland de ciertas ciudades portuarias, muchas de las mercancías llegadas a ellas iban destinadas, en última instancia, a la redistribución hacia otras regiones. Así ocurría, por ejemplo, con los textiles ingleses que desde Hamburgo eran conducidos por tierra a Polonia. Por tanto, otro capítulo pendiente en el estudio de este comercio marítimo es averiguar hasta qué punto estaban relacionados qué puertos con qué regiones, y si hubo cambios en el transcurso del tiempo, relacionando rutas marítimas, ciudades portuarias y territorios ${ }^{26}$.

El marco institucional del comercio hispano-holandés en relación con el Báltico registró un hecho clave en 1625, con la creación de la Sociëteit van de Levantse Handel, quedando la ruta vinculada a las normas que el Almirantazgo de Amsterdam fue produciendo tanto para el Mediterráneo como para el Báltico. El establecimiento de una comptoir u oficina de la sociedad en Cádiz pretendía controlar la llegada a este puerto de los convoyes que, en la mayor parte de los casos, procedían directamente de los puertos bálticos. La idea braudeliana de que ambos mares constituían un 
"double-sea-space" imbuía ya el espíritu de las sucesivas legislaciones que basaban este comercio en el intercambio de mercancías producidas en áreas tan distantes, complementado por la gran demanda de coloniales y de materiales navales, negocios de los que, quizá, las firmas neerlandesas extraían la mayor parte de sus beneficios, a juzgar por el notable tonelaje de tales productos transportado por sus buques $^{27}$. A partir de 1695, los directores de otra de las compañías de monopolio organizadas, la Sociedad para el Comercio y las Compañías dedicadas al Báltico (Directie van de Oostersche Handel en Reederijen, DOHR), trataron también de regular la organización de estos convoyes y la práctica de los fletamentos contratados en Amsterdam con destino a puertos a un lado y otro de la ruta ${ }^{28}$. Para el siglo XVIII, las fuentes generadas por la organización interna de estas compañías ofrecen información atinente, sobre todo, a las rutas completas llevadas a cabo por estos viajes de negocios. La proliferación de compañías comerciales en la República Holandesa hizo posible la existencia de registros de salidas y entradas de buques, los Galjootsgeldregisters. Entre 1709 y 1825, estos registros fueron anotados por la Directie van de Oostersche Handel en Reederijen. También son importantes los recogidos, a partir de 1716, por la Directie van de Moscovische Handel, especialmente para el análisis de las conexiones con los puertos rusos y aquellos otros situados más allá de la Península Escandinava ${ }^{29}$. Estas fuentes son complementarias de los contratos de fletamentos realizados en Amsterdam y, por supuesto, de los verhoogde last-en veilgeld cobrados en el Almirantazgo de Amsterdam. Hay que señalar que la mayor parte de los fletamentos con destino a Cádiz se realizaba en puertos neerlandeses, por lo que apenas se han localizado contratos en los documentos notariales gaditanos ${ }^{30}$.

A comienzos del siglo XVIII, las mercancías conducidas por esta ruta no experimentaron, en su mayoría, un cambio drástico respecto de los acaecidos durante el siglo XVII. Sí hay indicios, no obstante, de alteraciones en las cantidades de ciertas mercancías y, sobre todo, en el almacenamiento y redistribución de coloniales desde Amsterdam y Cádiz, como centros de provisión principales. En este sentido, Cádiz sirvió de escala complementaria a Amsterdam en lo que se refiere a los stocks de productos coloniales, entre los que se incluían también los asiáticos, debido al atraque

27 Braudel (1972), I, p. 276; Ormrod (2003), p. 60, Crespo (2000), pp. 32-90.

28 GAA, Archief van de Directie van de Oostersche Handel en Reederijen, 1: Memoriaal, Verslag van de handelingen van de gecommitteerden uit de kooplieden handelende op de Oostzee, 1 deel 1702-1706; Brakel (1910); Tielhof (1999); Daalder (1998).

$29 \quad$ Van Eeghen (1951).

30 GAA, Archief Oostersche Handel en Reederijen. Para los Galjootsgeld (años 1705 y 1715), legs. 94, 95, 96 y 97. Buck y Lindblad (1990), pp. 27-48. Estos testimonios complementan la información de los documentos notariales que están en el mismo archivo (véanse las fuentes del Gráfico 3). Se ha hecho una crítica de estas fuentes en términos comparativos en Crespo (2000), p. 18. Welling (1998) los ha usado a partir de la década de 1740. GAA, Archief van Burgemeesters, legs. 164-171 (años 1702-1711). 
cada vez más frecuente en este puerto de los buques de la Compañía de las Indias Orientales holandesa (VOC) ${ }^{31}$. El tráfico seguía basándose en el transporte de arenques, pescados diversos (sobre todo los de tipo haring, o en salazón), grano y cereales, así como madera y metales, con destino a puertos andaluces. También se introdujeron textiles y paños, procedentes casi todos de firmas flamencas de Gante o Amberes. Las firmas de Amsterdam hallaron un negocio próspero al convertirse en los principales mediadores en la salida atlántica de una buena parte de la producción de Flandes y Brabante. En cuanto a estos productos, sólo se registraron altibajos e inflexiones regulares según las coyunturas. Junto al incremento de las reexportaciones de coloniales, también conoció una gran alza el transporte de materias primas para la industria, sobre todo naval, incluyendo ciertos productos metalúrgicos, como el hierro. La navegación holandesa fue una activa mediadora de estas importaciones, que compensaron, en buena parte, la disminución del capítulo de grano y cereales. En la primera mitad del siglo XVIII se incrementó también el comercio de importación de maderas de centros como Viborg y de hierro de Suecia. Desde los puertos suecos, por ejemplo, el hierro había sido el producto más comercializado por los holandeses, según Lindblad, entre 1694 y 1695, y aún conoció cierto auge durante la primera mitad del XVIII ${ }^{32}$. Los negocios de reexportación de coloniales conocieron un alza moderada pero evidente entre 1681 y 1731, según las cifras recogidas por Posthumus, antesala del otro gran período de crecimiento situado a partir de 1730 . En este grupo se encontraban, sobre todo, el azúcar, el café, el tabaco y la pimienta ${ }^{33}$. Paralelamente, desde finales del siglo XVII se había producido un gran aumento del negocio exportador, que incluía también remesas de capitales para sostener el comercio de las compañías en los diversos puertos situados a lo largo de la ruta.

De ahí que, durante los críticos años de comienzos del Setecientos, resultase más rentable que nunca para las casas comerciales de Amsterdam establecer un diseño que vinculara las dos partes del viaje: primero, los buques de la flota se dirigían a diversos puertos bálticos, especificándose en los contratos de fletamentos la prioridad del flete con destino a los mismos; después, desde ellos, se dirigían normalmente a puertos de la cornisa atlántica europea, franceses sobre todo, y a los del sur de la Península Ibérica y del Mediterráneo. Al ser las reederijen medianas y pequeñas firmas de negociantes y dueños de navíos, que en muchos casos también actuaban como capitanes a bordo de los mismos, la existencia de estos fletamentos concertados, previa comprobación por el Almirantazgo y la Directie, daba libertad para que, una vez que los barcos atravesaban el Sund, la flota se dividiese hacia distintos des-

Steensgaard (1990), p. 105; Crespo (1998), pp. 145-154.

Lindblad (1994), pp. 205-228; Schokkenbroek (1994), pp. 11-14.

Posthumus (1943), vol. 1. 
tinos. Era una ruta larga en la que se practicaba el "port á port" (cabotaje), que tenía al Sund danés y a la isla de Texel (al norte de la provincia de Noord-Holland) como escalas de descanso y reorganización antes de tomar la ruta atlántica al regreso del Báltico. Los contratos de fletamentos hechos para puertos bálticos estaban planteados para conectar con los puertos meridionales, teniendo a Cádiz como escala principal para otras conexiones, el Mediterráneo e, incluso, las colonias españolas de América $^{34}$.

Con el tiempo, quizá la razón principal de las ventajas del transporte neerlandés radicaba en la oferta que las firmas ponían a disposición de sus clientes y socios. La forma en la que se organizaba el transporte ponía a disposición de los exportadores una especie de oferta múltiple, un "paquete" de fletes baratos, seguro para el viaje y capital para comprar mercancías en las ciudades portuarias que tocaba la ruta. Esto era primordial para unas economías regionales como las de las provincias bálticas, con gran riqueza de recursos naturales pero con pocos medios para exportarlos. En este punto, la labor de las firmas comerciales foráneas asentadas en ciudades como Estocolmo, Dantzig, Riga o Arcángel hizo que estos puertos se convirtieran en auténticos centros de almacenamiento y distribución, casi sucursales del entrepot de Amsterdam $^{35}$. Tradicionalmente, se ha considerado que ésta era la razón de que los barcos holandeses fueran más rentables que los buques hanseáticos o ingleses. De hecho, hay indicios de que algunas casas de comercio británicas y de Hamburgo preferían los fletes y seguros baratos que proporcionaban sus socios de Amsterdam. Este auténtico "paquete" de negocios hacía rentable el viaje de comercio tanto a los fletadores como a las compañías de comercio. Esta realidad sólo era cuestionada por problemas de disponibilidad de buques en ciertas coyunturas bélicas.

Gracias al análisis combinado de las fuentes antes citadas puede observarse que las economías regionales vinculadas a las rutas de los convoyes holandeses experimentaron diversas fluctuaciones a partir de 1700, coincidiendo (como se aprecia en el Gráfico 4) con el trasiego de los conflictos bélicos. Según los datos comparativos recogidos por Ormrod, entre 1702 y 1713 el comercio holandés del Báltico sufrió una regresión, parecida a la experimentada por Inglaterra ${ }^{36}$. Al parecer, las economías regionales bálticas se vincularon crecientemente al Atlántico en términos mercantiles, sobre todo debido a la introducción de productos coloniales, en aumento durante las últimas décadas del siglo XVII, punto éste que provocó las mayores fricciones entre Gran Bretaña y Holanda, sobre todo después de 1700. Pese a ello, el gran crecimiento del movimiento portuario de productos coloniales en Amsterdam hace dudar, al

Crespo (2000), pp. 116-135.

Lesger y Noordegraaf (1995); Crespo (2002), II, pp. 443-469.

Ormrod (2003), pp. 60 y ss. 


\section{GRÁFICO 4}

NÚMERO DE NAVÍOS EN LA RUTA AMSTERDAM-CÁDIZ, 1700-1710

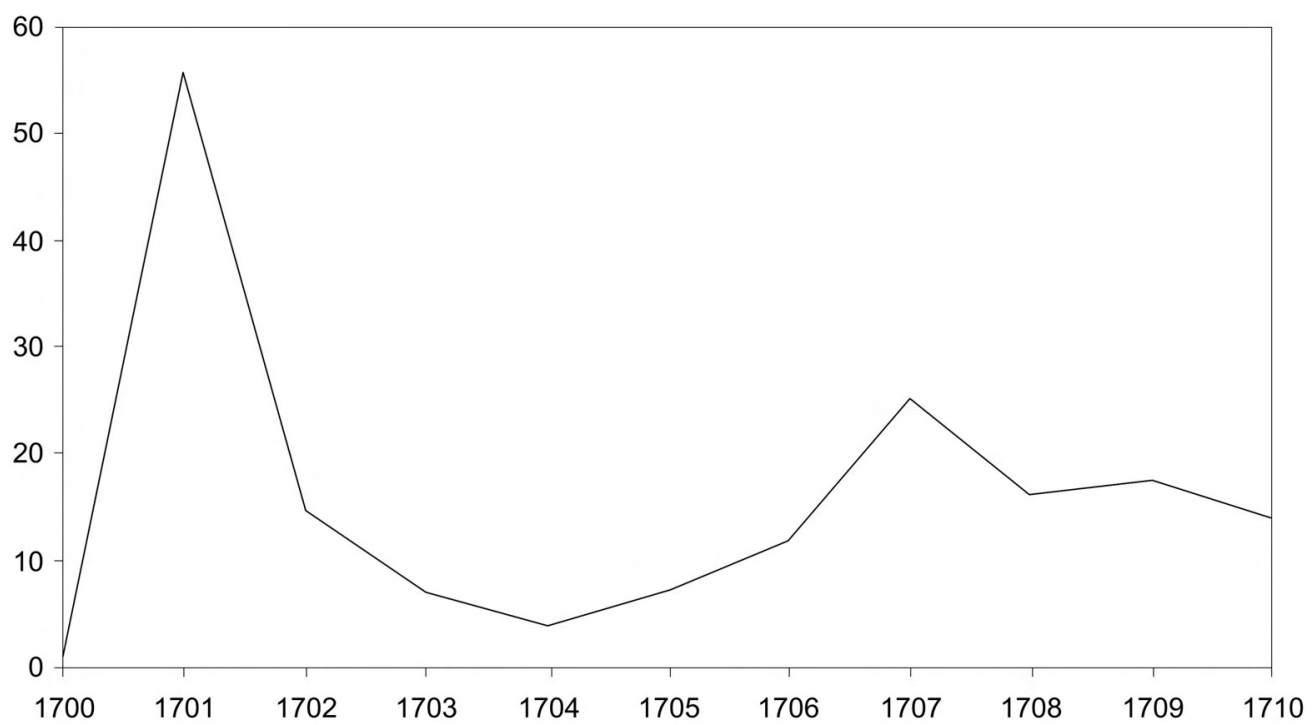

Fuentes: GAA, Notarial Archieven, 6677B/415-429; 6678A/331; 5889/1785-1777; 2943/21; 5905/521; 7214/1009; 5000/1223; 6684/658; 4654/367-368; 4656/464; 4217/651; 7355/704; 4620/257; 7355/423 (Notario Jan Valkenburg, documentos en español); 7948A/23; 6593/1091; 6594/¿?; 3353/991; 3710-1/142; 3350/1316; 5879/1089; 3350/1370; 5287/667-1583-1639; 6903/313; 5287/959-1471-1479-1507; 2287/187-211-236; 5879/543-599-1118; 3351/623-1075; 6903/827; 6561/569; 6562/235; 3351/1843-2035; 5881/983; 3352/1455; $3353 / 2273 ; 5288 / 1203 ; 3353 / 1359-1171 ; 3729 / 712 ; 2941 / 1613 ; 3729 / 770-772 ; 3354 / 697 ; 5289 / 249$; 6594/290; 5289/325; 3354/1067; 4988/529; 3355/317; 3356/51-339; 5886/451; 6565/736; 5291/1941; 6567/115; 4200/1257; 6409/731; 4205/445; 4206/425; 5900/817-953; 7281/11; 7285/275; 6771/759; 6772/23; 5903/1107; 7283/285; 6774/303; 5674/777; 7286/1115; 6413/925; 5909/933; 7287/57-1251; 5910/893; 6613/371; 6614/889; 5913/923; 5116/311-318. Y GAA, "Brieven met Cadiz" 6676B; 5111, 1579; 4192/579; 5879/837; 5391/361; 2941/333 у 1129; 6031/143; 2941/577; 6561/1277; 5391/1035; 4621/865; 6455/1558. Crespo (2000), p. 143.

respecto, del éxito británico: había muchas firmas asentadas en la ciudad, una buena parte de ellas judías, que controlaban la redistribución de tales productos ${ }^{37}$.

Aparte de los datos sobre navegación, las fuentes notariales ofrecen información sobre la naturaleza de este comercio y la actitud de las firmas comerciales ante la crisis y la guerra. Al igual que sucedió en otras ciudades donde se asentaron, una de las razones de esta decadencia en tiempos de guerra fue la marcha precipitada de algu-

$37 \quad$ Steensgaard (1990), pp. 103-152. 
nas firmas notables de Cádiz. ${ }^{38}$ Uno de los negocios más boyantes, el de importación de madera para la industria naval, se vio gravemente perjudicado por los asedios rusos a algunos puertos del norte. Eran varias las firmas holandesas que mantenían negocios de aprovisionamientos navales en Cádiz, incluso con asientos firmados con la Casa de la Contratación o con la Intendencia de Marina. Una de ellas, la casa de la Viuda Wittebol \& Co., se vio negativamente afectada por el inicio de la guerra en 1700. En 1699, su socio en Cádiz, Laurenzo Overbeecq E Co., se marchó a la República ante la incertidumbre provocada por el difícil acceso a los almacenes de mercancías ubicados en algunas ciudades portuarias bálticas y el consiguiente descenso de la navegación ${ }^{39}$. Otras casas, sin embargo, continuaron enviando pertrechos a la armada durante toda la década siguiente ${ }^{40}$. A pesar de las dificultades de la guerra, en Amsterdam se formaron algunas compañías para comerciar con Cádiz, cuyos contratos contemplaban la posibilidad de un viaje de negocios. En abril de 1702 se firmó una compañía (la segunda en su caso) entre Jacob Smit, ya residente en Cádiz, y Jan Wesseling. En ese año también se firmó compañía entre Jan Lijnslager y Cornelis Rost $^{41}$. Otros, no obstante, regresaron a su patria, como Pieter de Yperen y Jacobus Cramer, tras una corta estancia en Cádiz ${ }^{42}$.

Pese a los problemas bélicos, el papel de las comunidades en estos puertos fue primordial para mantener el negocio y permitir la sobrevivencia del comercio luego de 1710. La actuación de las casas comerciales neerlandesas, y la de aquéllas de otras nacionalidades norteñas vinculadas a su red familiar y empresarial (como las suecas o las hanseáticas, principalmente), explican el mantenimiento y el posterior remonte de este comercio en tiempos de guerra. Estas firmas contaban con redes muy extendidas por ciudades bálticas y escandinavas, siendo Cádiz uno de sus principales emporios por ser un puerto al que arribaba el metal precioso. Las casas comerciales repetían casi las mismas coordenadas: el asentamiento de una colonia de mercaderes, la extracción de un producto que daba más beneficio y el transporte en navíos holandeses entre distintas escalas. Su estrategia se basaba principalmente en la financiación, en un año determinado, de una gran operación de cuya suerte dependía el curso de los negocios posteriores. Los miembros de estas familias viajaban y se asentaban, en ocasiones, en otros puertos. Las compañías no basadas en lazos familiares eran menos frecuentes, pero era normal el uso del factor que residía en el puerto

38 Sobre las comunidades mercantiles extranjeras de Cádiz hay recientes aportaciones que, además de ofrecer una nueva visión desde el punto de vista metodológico, aportan información novedosa sobre el protagonismo de aquéllas, lo que ha permitido superar algunos de los supuestos teóricos impuestos por obras clásicas como la de Girard (1932). Véanse, Bustos (2005), García Fernández (2005), Weber (2004) y Crespo (2001). 
base, desde donde se hacían las extracciones, que estaba sujeto por un contrato con la compañía matriz. En este caso, se firmaba también un dienscontract (contrato de oficina), como sucedía en Cádiz en los años posteriores a $1713^{43}$.

En el caso gaditano, la cercanía del mercado americano proporcionaba, pese al inicio de la guerra, muchas perspectivas de beneficios. Aunque el ataque y hundimiento de la flota de Nueva España en Vigo, en 1702, produjo un gran desasosiego entre las firmas y una inflexión total en la ruta, el comercio que nos ocupa experimentó un leve, pero creciente, repunte a partir de 1705 y 1706. La navegación entre Amsterdam y Cádiz, muy buena en 1700 y 1701, conoció un colapso total en 1702, caracterizado por la salida de los negociantes holandeses de la ciudad andaluza. Ello fue paralelo a una crisis generalizada que se produjo en la misma, incluyendo el asalto y saqueo que sufrió en ese mismo año, la ruptura del comercio con las Indias e, incluso, un ciclo epidémico que mermó su población. Pero, por decaído que quedase el comercio, firmas de Amsterdam, como las de Hendrik Koop (que aparece como hoofdreder o principal cargador o fletador), Adriaen van Aldewereld, Raphael Luberto $\mathcal{E}$ Abraham e Isaac Da Rocha, con sus correspondientes en Cádiz como Hertog Creug $\mathcal{E}$ Möller, Carlo Panhuys \& Co., siguieron fletando pequeñas flotas con destino a Cádiz en los años de mayor virulencia bélica. Naturalmente, en los contratos de fletamentos firmados en Amsterdam se consignó que las mercancías se cargaban "corriendo riesgo", y los seguros marítimos registraron una clara subida ${ }^{44}$.

Aunque el eje Amsterdam-Cádiz había servido tradicionalmente para acceder al área mediterránea, las colonias españolas se perfilaron cada vez más como destino primordial de los negocios de las firmas de Amsterdam a partir de la década de 1660. Ante la paulatina decadencia del Mediterráneo, la mayor parte de las casas de comercio de la ciudad holandesa parecían vivir pendientes del comercio de Cádiz y la llegada de las flotas. En estos años eran las flotas de Nueva España y los buques de Buenos Aires los que acaparaban la mayor atención, pues muchas firmas tenían dinero embarcado en tales naves. Algunas de ellas eran judías, como la firma de Violante Curiel y su esposo Francisco Nunes da Costa, fallecido poco después ${ }^{45}$. Se ha comprobado que estas casas de comercio colaboraban, en sus actividades, también con firmas británicas y con familias flamencas de Cádiz. En mayo de 1701, una firma de Bruselas (la de María Agatha Baeles) remitió unas pacas con textiles (brocados) por mediación de Antonio de Prados y Jacob Roeters, cargadores en Amsterdam. El cargamento se envió a los consignatarios Edward Gardner \& Thomas Martin Co., y consistía en 1.445,5 varas españolas (repartidas en 9 cajones o stukken) a 14 pesos la vara.

\footnotetext{
$43 \quad$ Lindblad (1982), p. 21; Crespo (2000), p. 42; Müller (1998).

44 GAA, Notarial Archieven, 6676B, y 4129, exp. 579.

45 GAA, Notarial Archieven, 6677B/415.
} 
Es sólo un caso ilustrativo ${ }^{46}$. Debido a la creciente crisis de los convoyes de Ostende, muchas firmas de Amberes redirigían sus encargos a Amsterdam y, desde allí, hacia los mercados españoles, con la esperanza de enlazar con las flotas americanas pero también inducidas por la creciente demanda de manufacturas textiles de la Baja Andalucía. Estas operaciones afectaban principalmente a los textiles, quizá por la preferencia flamenca por las ciudades de los Países Bajos septentrionales y no por Francia, que intentaba, por su parte, controlar el comercio de los negociantes flamencos ${ }^{47}$.

Los buques holandeses acostumbraban a dejar almacenadas en Cádiz mercancías procedentes de puertos como Dantzig o San Petersburgo. En contrapartida, solían comprar productos españoles para introducirlos en los puertos bálticos. En 1703, Harmen Warsinck, vendedor de vino de Amsterdam, dio poder en blanco a Paulus Nieman, de Dantzig, para vender las mercancías que había vuelto a recoger en Cádiz y enviarlas al puerto báltico junto con un cargamento de vinos españoles. Nieman debía al de Amsterdam la cantidad de 253 "carolusgulders" (sic) por la compra de estos productos ${ }^{48}$.

En general, entre 1702 y 1708, los negocios holandeses con Cádiz conocieron años aciagos. Sólo para el último año citado vuelven a tenerse noticias de la reapertura de la firma de compañías interesadas en el comercio gaditano. En julio de ese año, se abrió la oficina (Kaantoor) entre Melchior de Ruuscher y Rodrigo Mels, en el Puerto de Santa Maria ${ }^{49}$. Sin embargo, ya en 1707 , se hizo un viaje de negocios a Sanlúcar de Barrameda en un buque de guerra comandado por el capitán Floriszoon Cruijtman y que fue cargado con mercancías a su vuelta a Amsterdam, con productos consignados a Pieter de Clercq ${ }^{50}$. En noviembre de 1708, también firmaron compañía Christián Duisberg y Gilberto de Bruijn, que luego serían activos comerciantes de Cádiz ${ }^{51}$.

La reactivación de la conexión con el Sund se hizo más evidente en 1709 y ello a pesar de los problemas de la guerra en los dos flancos: En este año, varios comerciantes de Amsterdam con intereses en el cargamento del navío De Graef Wachtmester, del capitán Hans Holm, que se perdió en ruta entre Amsterdam y Cádiz, tuvieron que rendir cuentas del siniestro ante Paulus Sijbrantsz de Copenhague y otros ciudadanos de puertos del Sund, como Riga, Goteborg o Reval ${ }^{52}$. Por último, hay que destacar que la ruta recobró cierta regularidad tras finalizar las dos guerras, en especial en 1717 y 1718. Ya entrada la década de 1720, el interés holandés en mantener la ruta hacia Cádiz se centró en nuevos motivos. Mientras que los enlaces con los puer-

\footnotetext{
GAA, Notarial Archieven, 6031/143.

Crespo (2002), pp. 454-467.

GAA, Notarial Archiven, 6678/331.

GAA, Notarial Archiven, 5905/521.

GAA, Notarial Archiven, 7214/1009.

La firma de esta compañía se hizo justo cuando ambos embarcaron en dirección a Cádiz para establecerse allí. GAA, Notarial Archiven, 5000/1223.

52 GAA, Notarial Archiven, 6684/658.
} 
tos mediterráneos habían decrecido considerablemente (31,5 por 100), los viajes hacia América empezaron a hacerse cada vez más importantes, aprovechando una serie de estrategias legales llevadas a cabo gracias a la connivencia de intereses con la nación flamenca de Cádiz (62,3 por 100). Ésta sería la pauta durante el resto de la centuria, registrándose desde entonces importantes altibajos al compás de los ritmos del monopolio gaditano ${ }^{53}$.

\section{Ventajas del "port á port" y la interrelación con otros puertos}

No era la primera vez que las crisis bélicas producían un tremendo desasosiego en las firmas comerciales que operaban con los puertos del sur peninsular, a lo que se unía la crisis estructural del Mediterráneo. Durante estos años críticos se produjeron algunos cambios en las distintas escalas entre puertos. El recrudecimiento de la guerra en el Báltico a partir de 1700 supuso la reducción del flujo comercial con algunos puertos, como Estocolmo y Krondstadt (que bajaron al 1 por 100 y al 3 por 100, respectivamente, en relación al total de las conexiones). Otros descensos importantes se registraron en Goteborg y Narvik, tradicional centro éste último del aprovisionamiento naval. Tras la recuperación de estas conexiones a partir de 1713, Viborg, San Petersburgo (gracias a las operaciones de la comunidad neerlandesa de Arcángel), Dantzig, Königsberg, Narva y Riga se convirtieron en los principales puertos de conexión antes de la salida de las flotas neerlandesas hacia el sur peninsular.

Respecto a los principales puertos conectados, hay que indicar que existía una tradicional relación económica y social entre las provincias neerlandesas y algunas naciones bálticas. Por ejemplo, con Suecia, a la que las unía un activo tráfico marítimo desde el siglo XVII. Algunas firmas holandesas lograron acceder al control de ciertos recursos naturales suecos, como la madera, que era redirigida hacia diversas ciudades de la fachada atlántica, entre ellas Cádiz. Algunas firmas, como la casa de la familia Marcus, Pieter y Abraham Pels, llegaron incluso a ejercer un monopolio real sobre las exportaciones de madera, pese a verse afectadas por el ascenso de la economía sueca en la segunda mitad del siglo XVII ${ }^{54}$. Pero fue sólo más adelante, con la creación en 1731 de la Compañía de las Indias Orientales sueca, cuando las firmas de este país empezaron a pugnar por tomar las riendas de sus propios negocios con el sur peninsular. No obstante, esta compañía de monopolio, que registró un tráfico regular en dirección a Cádiz desde esa fecha, se había inspirado para el diseño de su ruta en la que los buques de la Compañía holandesa de las Indias Orientales

\footnotetext{
53 Crespo (2004); Klooster (1995), pp. 41-58.

54 Lindblad (1982), p. 21; Lesger y Noordegraaf (1995), pp. 77-85, 85-101, y 147.
} 
(Vereenigde Oostindische Compagnie) hacían en sus viajes a Oriente ${ }^{55}$. No obstante, los acuerdos diplomáticos entre suecos y rusos favorecieron un nuevo aumento de la presencia holandesa en el Báltico a partir de 1730. En Estocolmo continuó asentada una pequeña colonia de prominentes negociantes de origen holandés, que sólo declinó en la segunda mitad del siglo XVIII. También en Dantzig una elite de mercaderes holandeses monopolizaba más del 50 por 100 del grano que se concentraba en este puerto para la exportación. Entre el 60 al 90 por 100 de los buques que partían cargados con grano desde esta ciudad, eran neerlandeses en la década final del siglo XVIII ${ }^{56}$.

La regularidad del cabotaje propició que las flotas neerlandesas ampliaran su radio de acción a otros puertos cercanos, algo que, sin duda, se incrementó a partir de la década de 1720. La necesidad de algunas zonas de tener una salida al mar, en un territorio climatológicamente hostil pudo ser una razón por la que esta vinculación fue incentivada por algunos centros mercantiles. Por ejemplo, entre Moscú y Arcángel, que era también un centro de construcción naval. Este puerto fue el único eslabón de Rusia con Occidente hasta 1700. Otro puerto interesante fue Krondstadt, construido por los suecos hacia 1703 al objeto de controlar, durante la guerra rusosueca, el único pasaje existente hacia el centro mercantil de San Petersburgo, razón por la que fue atacado por los rusos. Por su parte, San Petersburgo era un centro mercantil cuya gran prosperidad se basaba en la construcción naval, una industria emergente alrededor del Ladoga que, al parecer, recibió mucha influencia neerlandesa ${ }^{57}$. El clima de esta zona era un factor a considerar. El mar y los ríos estaban helados durante buena parte del año y, en muchas ocasiones, los convoyes que luego partirían hacia la Península Ibérica se veían forzados a invernar en los puertos de Riga, Reval, San Petersburgo o Arcángel. No se sabe hasta qué punto ello influyó en un aumento espectacular de esta conexión a partir de 1715. Así, el mapa de puertos involucrados en esta conexión báltica se amplió entre 1718 y 1765, provocando el posterior crecimiento del acceso a estos puertos de los convoyes que luego relacionarían Cádiz con algunos puertos bálticos y del norte de Europa.

Otra conexión relevante que se sumó a las escalas del "port á port" neerlandés fue la mantenida con Hamburgo, que se convirtió en puerto de entrada del vino y las lanas españolas que luego se redistribuían por otros puertos bálticos. En el caso de la lana, Cádiz compitió con Bilbao como puerto de salida, aunque los ejemplos del papel desempeñado por la capital andaluza son escasos. En julio de 1703, la firma Conraed Block e Hijos, declaró que había ordenado el cargamento de 12 balas de lana española, compradas en abril en Cádiz por medio de su socio Gaspar Tames, y enviadas a Hamburgo a su hermano Simón Tames, en el navío holandés De Croon. Los Block

\footnotetext{
$55 \quad$ Koninckx (1980), p. 26; Müller (2004), pp. 75 y ss.

$56 \quad$ Lindblad (1982), pp. 26 y 50.

57 Hughes (2000).
} 


\section{GRÁFICO 5}

LA CONEXIÓN BÁLTICA EN 1718 Y 1765 EN RELACIÓN A LA RUTA AMSTERDAM-CÁDIZ

(número de buques y puertos de escala)

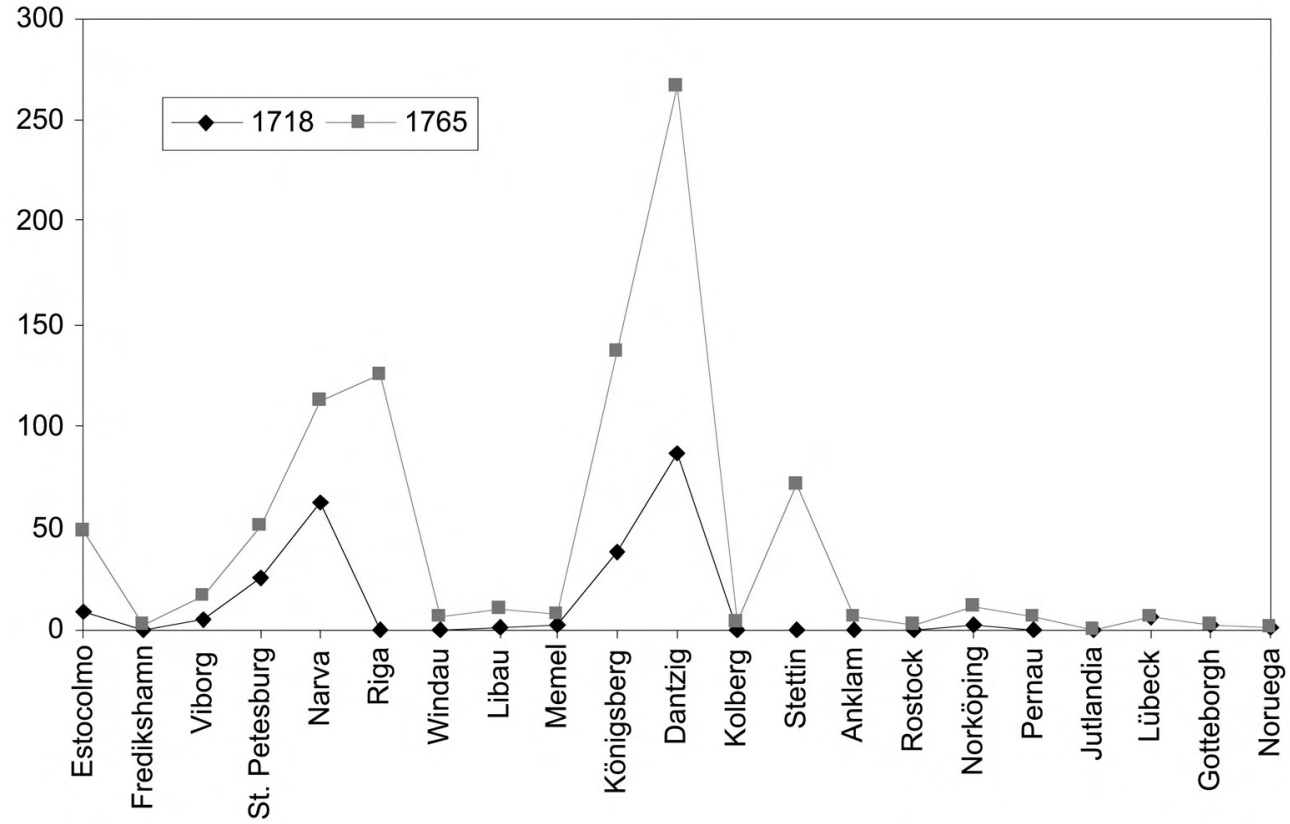

Fuentes: GAA, Archief Oostersche Handel en Reederijen, 1694-1823 (Archief 78): 178. Crespo (2000), p. 100.

declararon que eran propietarios de la lana y que esta había sido pagada "van uitstaande rekeningen in Spanje" ("por cuentas salientes en España"); es decir, a través del dinero depositado en manos de sus consignatarios en el puerto gaditano y mantenido por la propia firma para el envío de productos a otras ciudades en donde estaban sus socios ${ }^{58}$. Por desgracia, este buque fue interceptado por piratas de Zelanda ("Zeeuwse") y llevado a un puerto de esta provincia 59 . Hay viajes a Hamburgo registrados entre 1703 y 1706, al igual que a Estocolmo, también en $1706^{60}$. Respecto al comercio de Suecia con Cádiz, importa destacar que, pese a que las flotas holandesas

58 GAA, Notarial Archiven, 5889/1785.

59 Conraed Block había efectuado en Cádiz una firma con Gilberto de Bruijn para cargar lana en dirección a Hamburgo, pero este negocio tropezó con muchas dificultades. GAA, Notarial Archiven, 5889/1777.

60 Caso del capitán Eric Höoien, que llegó a Cádiz para cargar aceite y lana. GAA, Notarial Archiven, $7281 / 11$. 
siguieron realizando esta conexión, los propios mercaderes suecos tomaron las riendas de su comercio con el sur de Europa, una de las razones quizá de que la conexión holandesa con Estocolmo y Cádiz disminuyera, registrándose un aumento del comercio directo sueco con Cádiz, sobre todo a partir de 1730. Varias firmas comerciales suecas negociaban con Cádiz, pero buena parte de ellas eran de origen holandés, como en el caso de Cornelio Cocq, que tenía una commissiehandel (comisión para comerciar) de junio de 1701. Este Cocq pertenecía a una familia de comerciantes neerlandeses que había viajado a Suecia para recoger algunos envíos que la familia tenía encargados desde puertos suecos para transportar al sur de España ${ }^{61}$.

\section{Reflexiones finales}

El continuo estado bélico influyó en las relaciones comerciales del Báltico con otras áreas europeas y pudo suponer, con el tiempo, la apertura de rutas alternativas, el planteamiento de un nuevo sistema en la organización del transporte e, incluso, un cambio, en la larga duración, en la estructura del comercio, debido al crecimiento de la demanda de ciertos productos. Desde la decadencia de la Hansa, diversas naciones habían competido por el papel de transportistas entre el Báltico y los puertos ibéricos y mediterráneos. Holandeses, ingleses y, en menor medida, naturales de los propios países bálticos, en especial suecos y ciudadanos de la urbe hanseática de Hamburgo, compitieron entre sí, aunque la primacía correspondió a los navegantes holandeses. En la segunda mitad del siglo XVII, Suecia sólo logró convertirse en exportadora de sus propios productos en algunos momentos claves en los que la República Holandesa resultó gravemente perjudicada por las guerras. En el tránsito del siglo XVII al XVIII, coincidiendo con el estallido de dos conflictos bélicos de gran envergadura, estas naciones se vieron envueltas en lo que iba a ser casi una guerra total. Las guerras bálticas y el conflicto sucesorio español indujeron grandes cambios en el equilibrio de fuerzas políticas en Europa, pero también afectaron de forma notable a los vaivenes de la navegación. La estructura del intercambio comercial, sin embargo, no se vio profundamente alterada, aunque existen indicios de cambio en el mapa de los puertos de introducción de algunas mercancías, orientados por la demanda de ciertos productos en amplias áreas geográficas. Los buques holandeses transportaban trigo, maderas y otros artículos de amplio consumo. Su papel mediador creció con el aumento de la demanda de productos coloniales en los países bálticos, y de frutos del Mediterráneo y de la Península Ibérica, como naranjas, vino, lana y otros. 
A pesar de la guerra y de las fluctuantes relaciones políticas, una serie de circunstancias favoreció el predominio del transporte holandés y el mantenimiento de la ruta entre Amsterdam y Cádiz. Una era la propia estructura del comercio, fortalecida por el aumento de la demanda y el interés por mantenerse en plazas mercantiles que, como Cádiz, servían de enlace de conexión al comercio entre diversas regiones. Otra tenía que ver con las propias técnicas comerciales aplicadas por las comunidades mercantiles, que garantizaban que los negocios pudieran mantenerse durante períodos largos. El "paquete" de fletes baratos y la forma en la que estaban organizadas las propias compañías o rederijen, con factor u oficina en Cádiz, constituían una manera de garantizar el mantenimiento de la ruta marítima. Ésta sobrevivió a duras penas durante los años de guerra, entre 1699 y 1720. Aparte de verse afectada por las tensiones que hicieron cambiar el mapa político del Báltico, también experimentó alteraciones en la interconexión entre puertos, debidas a los diversos asedios que sufrieron algunas ciudades portuarias y a la cambiante jerarquía de las escalas entre éstas. El peligro que corrió la conexión de dos espacios económicos tan complementarios e interconectados de forma secular, a través de un eje marítimo principal, sólo logró superarse por el afán de las casas de comercio extranjeras de Cádiz por mantener una ruta de la que dependía, en buena medida, su razón de ser y su propia supervivencia.

\section{Fuentes}

Gemeente Archief Amsterdam (Archivo Municipal de Amsterdam)

a) Archief nr. 5050 y 5052: Archief van Burgemeesters: Stukken betreffende de controle op de ontvangst van het verhoogde last-en veilgeld, leg. 164-171 (1702-1711).

b) Archief van de Directie van de Oostersche Handel en Reederijen, "Memoriaal, Verslag van de handelingen van de gecommitteerden uit de kooplieden handelende op de Oostzee", 1 deel 1702-1706. Archief 78, legs. 94, 95, 96 y 97 y 178.

c) Notarial Archieven (Archivos Notariales): 6677B/415-429; 6678A/331; 5889/1785-1777; 2943/21; 5905/521; 7214/1009; 5000/1223; 6684/658; 4654/367-368; 4656/464; 4217/651; 7355/704; 4620/257; 7355/423; 7948A/23; 6593/1091; 6594/ i?; 3353/991; 3710-I/142; 3350/1316; 5879/1089; 3350/1370; 5287/667-1583-1639; 6903/313; 5287/959-1471-1479-1507; 2287/187-211-236; 5879/543-599-1118; 3351/623-1075; 6903/827; 6561/569; 6562/235; 3351/18432035; 5881/983; 3352/1455; 3353/2273; 5288/1203; 3353/1359-1171; 3729/712; 2941/1613; 3729/770-772; 3354/697; 5289/249; 6594/290; 5289/325; 3354/1067; 4988/529; 3355/317; 3356/51-339; 5886/451; 6565/736; 5291/1941; 6567/115; 4200/1257; 6409/731; 4205/445; 4206/425; 5900/817-953; 7281/11; 7285/275; 
6771/759; 6772/23; 5903/1107; 7283/285; 6774/303; 5674/777; 7286/1115; 6413/925; 5909/933; 7287/57-1251; 5910/893; 6613/371; 6614/889; 5913/923; 5116/311-318.

c) Notarial Archief-Bestand Brieven met Cadiz, (Correspondencia con Cádiz), 6676B; 5111, 1579; 4192/579; 5879/837; 5391/361; 2941/333 y 1129; 6031/143; 2941/577; 6561/1277; 5391/1035; 4621/865; 6455/1558. 7190/85-87, 3356/1457, 12 ; 5291/1589; 6676B; 4129, exp. 579; 6031/143, 6678/331, 5889/1785, 5889/1777, 7281/11, 5391/1035, 5905/521, 7214/1009, 5000/1223, $6684 / 658$.

Nationaal Archief, La Haya

Archief van de Gezanten en consuls in het buitenland tot 1813. Inventaris Zweden, Pruisen, Polen, Saksen. Gezantes van de Staten Generaal in Zweden in de periode 1674-1806.

a) Stukken bettreffende de grote Noordsee oorlog, 1699-1700, leg. 25 y 26.

b) Stukken bettreffende de Spaanse Successie oorlog, 1701-1704, leg. 27.

\section{Biblioteca Nacional, Madrid}

Memorial de los Señores Embaxadores Extraordinarios de Su Real Majestad de Suecia, entregado a Sus Altezas los Señores Estados Generales de las Provincias Unidas en 18 de Avril de este año de 1673, La Haya.

\section{Bibliografía}

ALEGRE, José Manuel (1978): Las relaciones hispano-danesas en la primera mitad del siglo XVIII, Copenhague, Études Romanes de l'Université de Copenhague.

ASTRÖM, Sven E. (1963): From Cloth to Iron: The Anglo-Baltic Trade in the late Seventeenth Century, Helsingfors.

BOTJÁR, Endré (1999): Foreword to the past: a cultural history of the Baltic people, New York, Central European University Press.

BRAUDEL, Fernand (1972): The Mediterranean and the Mediterranean world in the Age of Philip II, Londres, Collins, 2 vols.

-(1974): Civilización material y capitalismo, Barcelona, Labor.

-(2005): "La economía del Mediterráneo del siglo XVII", en NADAL, Jordi, y PAREJO, Antonio (coords.), Mediterráneo e Historia Económica, Almería, Caja Rural Intermediterránea, pp. 115-137.

BRUIJN, Jaap R. de (1970): De Admiraliteit van Amsterdam in rustige jaren, 1713-1751, Amsterdam, Haarlem. 
BUCK, Peter de, y LINDBLAD, J. Thomas (1990): “Navigatie en negotie. De Galjootsgeldregisters als bron bij het onderzoek naar de geschiedenis van de Oostzeehandel in de achttiende eeuw", Tijdschrift voor Zeegeschiedenis, 9, pp. 27-48.

BUSTOS RODRÍGUEZ, Manuel (2005): Cádiz en el sistema atlántico: la ciudad, sus comerciantes y la actividad mercantil (1650-1830), Cádiz, Universidad de Cádiz y Ed. Sílex.

BUTEL, Paul (1997): Européens et espaces maritimes (vers 1690-1790), Bordeaux, Presses Universitaires de Bordeaux.

CRESPO SOLANA, Ana (1996): La Casa de la Contratación y la Intendencia General de Marina en Cádiz, 1717-1730, Cádiz, Universidad de Cádiz.

-(1998): “La ruta del Levante: Cádiz en el tráfico marítimo neerlandés con sus mercados mediterráneos y orientales en los siglos XVII y XVIII", en Economía Marítima, Actas del 13 Encuentro de Historia y Arqueología, San Fernando, Cádiz, Ayuntamiento de San Fernando, pp. 145-154.

-(2000): El comercio marítimo entre Amsterdam y Cádiz (1713-1778), Madrid, Banco de España, Estudios de Historia Económica.

-(2001): Entre Cádiz y los Países Bajos. Una comunidad mercantil en la ciudad de la Ilustración, Cádiz, Fundación Municipal de Cultura, Cátedra Adolfo de Castro.

-(2002): "Las comunidades mercantiles y el mantenimiento de los sistemas comerciales de España, Flandes y la República Holandesa, 1648-1750", en CRESPO SOLANA, Ana, y HERRERO SÁNCHEZ, Manuel (coords.), España y las 17 Provincias de los Países Bajos: una revisión historiográfica (siglos XVI-XVIII), Córdoba, Universidad de Córdoba, Ministerio de Asuntos Exteriores y Fundación Carlos de Amberes, 2 vols., $2^{\circ}$ vol., pp. 443-469.

-(2004): "Dutch Trade with the Spanish West Indies and the Flemish merchant Community in Cadiz in the Eighteenth century: A community of shared interests?", www.ics.ul.pt/aphes2004/prog/pdf/D4AnaCrespoSolana.pdf, XXIV Encontro da APHES.

CRESPO SOLANA, Ana, y HERRERO SÁNCHEZ, Manuel (coords.) (2002): España y las 17 Provincias de los Países Bajos: una revisión historiográfica (siglos XVI-XVIII), Córdoba, Universidad de Córdoba, Ministerio de Asuntos Exteriores y Fundación Carlos de Amberes, 2 vols.

DAALDER, Remmelt (ed.) (1998): Goud uit Graan. Nederland en het Oostzeegebied, 1600-1850, Amsterdam, Nederlands Scheepvaartmuseum.

ECHEVARRIA BACIGALUPE, Miguel Ángel (1986): “Un episodio en la guerra económica hispano-holandesa: el decreto Gauna (1603)", Hispania, XLVI, pp. 57-98.

-(2002): "Sistemas productivos y espacios económicos: los Países Bajos en la España Imperial, 1500-1621", en CRESPO SOLANA, Ana, y HERRERO SÁNCHEZ, Manuel (coords.), España y las 17 Provincias de los Países Bajos: una revisión historiográfica (siglos XVI-XVIII), Córdoba, Universidad de Córdoba, Ministerio de Asuntos Exteriores y Fundación Carlos de Amberes, 2 vols., $2^{\circ}$ vol., pp. 494-511. 
ELLINGER, Bang (1906-1933): Tabeller over skibsfart og varetransport gennem Oresund, 1497-1660, 3 vols, Copenhagen, Gyldendal Nordisk Forlag.

FABER, Johannes A. (1966): “The Decline of the Baltic trade grain-trade in the second half of the Seventeenth century", Acta Historiae Neerlandandica I, pp. 108-131.

-(1988): "Structural changes in the European economy during the Eighteenth century as reflected in the Baltic Trade", en HEERES, Willem G., y NOORDEGRAAF, Leo (eds.), From Dunkirk to Dantzig: Shipping and Trade in the North Sea and the Baltic, 1350-1850, Hilversum, Verloren, pp. 83-115.

-(1989): "De Sundvaart als spiegel van de structuurveranderingen in de Europese economie gedurende de achttiende eeuw", Tijdschrift voor Zeegeschiedenis, 8, pp. 91-100.

FEDEROWICZ, Jan Krzysztof (1980): England's Baltic trade in the early seventeenth century: a study in Anglo-Polish commercial diplomacy, Cambridge, Cambridge University Press.

GARCÍA FERNÁNDEZ, M. Nélida (2005): Comunidad extranjera y puerto privilegiado: Los británicos en Cádiz en el siglo XVIII, Cádiz, Universidad de Cádiz.

GERSON, D. James y VAUGHN, Ernest V. (eds.) (1912): Studies in the History of English commerce in the Tudor period, New York, Appleton \& Co.

GIRARD, Albert (1932): Le commerce français à Séville et Cadiz en temps des Habsbourg: contribution à l'étude du commerce étranger en Espagne aux XVI et XVII siècles, Paris, Bordeaux.

GÓMEZ-CENTURIÓN, Carlos (1988): Felipe II, la empresa de Inglaterra y el comercio septentrional: 1566-1609, Madrid, Instituto de Historia y Cultura Naval.

GUIMERÁ RAVINA, Agustín (1982): "Guerra internacional y comercio atlántico: el caso de Canarias en el siglo XVIII", V Coloquio de Historia Canario-Americana, Coloquio Internacional de Historia Marítima, Tomo IV, Las Palmas de Gran Canaria, pp. 457-471.

HEERES, Willem G., y NOORDEGRAAF, Leo (eds.) (1988): From Dunkirk to Dantzig: Shipping and Trade in the North Sea and the Baltic, 1350-1850, Hilversum, Verloren.

HEERINGA, K. (1917): Bronnen tot de Geschiedenis van den Levantschen Handel, Grote Serie 34, vol. 2, 1661-1726, La Haya, M. Nijhoff.

HERRERO SÁNCHEZ, Manuel (2000): El acercamiento hispano-neerlandés (1648-1678), Madrid, CSIC.

HUGHES, Lindsey (2000): Peter the Great and the West: new perspectives, New York, Palgrave.

IJZERMAN, Jan Willem (1931): “Amsterdamsche bevrachtingscontracten 1591-1602: 1. De vaart op Spanje en Portugal", Economische Historische Jaarboek, XVII, pp. 163-291.

ISRAEL, Jonathan I. (1988): “España, los embargos españoles y la lucha por el dominio del comercio mundial, 1585-1648", Revista de Historia Naval, 23, pp. 89-105. 
-(1990): "The Phases of the Dutch Straatvaart, 1590-1713: A chapter in the Economic History of the Mediterranean" en ISRAEL, Jonathan I., Empires and entrepots: the Dutch, the Spanish monarchy and the Jews, 1585-1713, London, Hambledon Press, pp. 133-162.

JANZEN, Olaf U. (ed.) (1998): Merchant organization and maritime trade in the North Atlantic: 1660-1815, St. John's, Newfoundland.

JEANIN, Pierre (1964): "Les comptes du Sund comme source pour la construction d'indices généraux de l'activité économique en Europe (XVIe-XVIIIe siècle) ", Revue Historique, CCXXXI, pp. 55, 102 y 307-340.

-(1971): "Die Hansestädte im Europäischen handel des 18. Jahrhunderts", Hansische Geschichtsblätter, 89, pp. 41-73.

JOHANSEN, Hans Christian (1987): "Hamburg Shipping in the Baltic 1784-1806", en SCHNEIDER, Jürgen, Wirtschaftskräafte und Wirtschaftswege III, Auf dem Weg zur Industrialisierung (= Beiträage zur Wirtschaftsgeschichte, Bd. 6), Stuttgart, pp. 233-249.

KAHK, Juhan, y TARVEL, Enn (1997): An Economic History of the Baltic Countries, Estocolmo, Almquist \& Wiksell International.

KLOOSTER, Willem W. (1995): Illicit Riches. Dutch Trade with the Spanish West Indies, Leiden, Konijnklijke Instituut voor Taal-Land en Volkenkunde.

KONINCKX, Christian (1980): The first and Second Charters of the Swedish East India Company (1731-1766), Kortrijk, Van Ghemmert.

KRAWHEL, Otto E. (1991): “Quellen zur Hamburger Handelsstatistik im 18. Jahrhundert", en FISCHER, Willem y KUNZ, Anthon (eds.), Grundlagen der Historischen Statistik von Deutschland: Quellen, Methoden, Forschungsziele, Verlagen, pp. 47-69.

LEMMINK, Jacques Ph. (1990): "Dutch convoys in the Baltic during the Russo-Swedish war, 1741-1743", en LEMMINK, Jacques Ph., y VAN KONINGSBRUGGE, Johannus Simon (eds.), Baltic Affairs. Relations between the Netherlands and Northeastern Europe, 1500-1800, Nijmegen, Institute for Northern and Eastern European Studies, pp. 161-204.

LESGER, Carel, y NOORDEGRAAF, Leo (eds.) (1995): Entrepreneurs and Entrepreneurship in Early Modern Times. Merchants and Industrialists within the orbit of the Dutch Staple market, Hollandse Historische Reeks, XXIV, La Haya.

LIEBEL, Hans (1965): “Laissez-faire vs. Mercantilism. The Rise of Hamburg \& the Hamburg Bourgeoisie vs. Frederick the Great in the Crisis of 1763" Vierteljahrschrift für Sozial und Wirtschaftgeschichte, 52, pp. 207-238.

LINDBLAD, J. Thomas (1982): Sweden's Trade with the Dutch Republic, 1738-1795, Van Gorcum, Assen.

-(1990), "Evidence of Dutch-Swedish trade in the 17th century", en LEMMINK, Jacques Ph., y VAN KONINGSBRUGGE, Johannus Simon (eds.), Baltic Affairs. 
Relations between the Netherlands and North-eastern Europe, 1500-1800, Nijmegen, Institute for Northern and Eastern European Studies, pp. 205-228.

-(1997): "Dutch Trade on Narva in the Eighteenth century", en HORSTMEIER, Carel y otros (eds.), Around Peter the Great. Three centuries of Rusian-Dutch Relations, Groninga, NOS.

MILLER, Milton E. (1987): "Naval Stores and Anglo-Russian Encounters in the Baltic: The English Expedition of 1715", en RUNYAN, Timothy J. (ed.), Ships, Seafaring and Society. Essays in maritime history, Detroit, Wayne State University Press, pp. 167-182.

MÜLLER, Leo (1998): The Merchant Houses of Stockholm, c. 1640-1800, A comparative Study of Early-Modern Entrepreneurial behaviour, Studia Historica Upsaliensia, 188, Uppsala.

-(2004): Consuls, Corsairs and Commerce. The Swedish consular Service and long-distance shipping, 1720-1815, Estocolmo, Uppsala Universiteit.

NEWMAN, Karin (1985): "Hamburg in the European Economy, 1660-1750", The Journal of European Economic History, 14, 1, pp. 57-93.

OAKLEY, Stewart P. (1993): War and Peace in the Baltic, 1560-1790, London, New York, Routledge.

ORMROD, David (2003): The Rise of Commercial Empires. England and the Netherlands in the Age of Mercantilism, 1650-1770, Cambridge, Cambridge University Press.

PALACIO ATARD, Vicente (coord.) (1989): España y el mar en el siglo de Carlos III, Madrid, Marinvest.

PIETSCHMANN, Horst (1992): "Hamburgo y la América Latina en la primera mitad del siglo XIX", I Congreso Internacional de Historia Económica y Social de la Cuenca del Caribe, 1763-1898, San Juan de Puerto Rico, pp. 455-485.

-(1998): “Un testimonio alemán desconocido sobre el comercio y la navegación en el Atlántico: la curiosa descripción de Friedrich Martens de una navegación de Hamburgo a Cádiz en 1671-1672", Actas del VII Congreso Internacional de Historia de América, Zaragoza, pp. 1.763-1.796.

POHL, Hans (1963): Die Beziehungen Hamburgs zu Spanien und dem Spanischen Ameri$k a$ in der zeit von 1740 bis 1806, Franz Steiner Verlag, Wiesbaden.

POSTHUMUS, Nicholaas W. (1943): Nederlandse prijsgeschiedenis, 3 vols., Leiden, Brill.

PULIDO BUENO, Ildefonso (1993): Almojarifazgos y comercio exterior en Andalucía durante la época mercantilista, 1526-1740, Huelva, Edición del autor.

SABATER GALINDO, Francisco (1990): Relaciones politicas y diplomáticas hispano-británicas durante el reinado de Felipe $V$, Madrid, Universidad Complutense de Madrid.

SÁNCHEZ BELÉN, Juan Antonio (2005): “El comercio holandés en la bahía de Cádiz en 1684", en MARTÍNEZ SHAW, Carlos (ed.), El sistema atlántico español: siglos XVII-XIX, Madrid, Marcial Pons, pp. 163-201. 
SANZ AYÁN, Carmen (1992): “Negociadores y capitales holandeses en los sistemas de abastecimientos de pertrechos navales de la Monarquía Hispánica durante el siglo XVII", Hispania, LII, 3, pp. 915-945.

SCHOKKENBROEK, J. C. A. (ed.) (1994): Plying between Mars and Mercury: Political, economic and cultural links between the Netherlands and Sweden during the Golden Age, La Haya, Embassy of Sweden.

STEENSGAARD, Niels (1990): "The Growth and Composition of the Long-distance Trade of England and the Dutch Republic before 1750", en TRACY, James D. (ed.), The Rise of Merchant Empires. Long-Distance Trade in the Early Modern World, 1350-1750, Cambridge, Cambridge University Press, pp. 103-152.

STOLS, Eddy (1971): De Spaanse Brabanders of de handelsbetrekkingen der Zuidelijke Nederlanden met de Iberische wereld, 1598-1648, Bruselas, Palais der Academiën, 2 vols., vol. 1, pp. 14-25.

TIELHOF, Milja van (1999): Directie der Oostersche Handel en Reederen, Amsterdam Contact.

VAN BRAKEL, Simon (1910): “De Directie van den Oosterschen Handel en Rederijen te Amsterdam", Bijdragen voor Vaderlandsche Geschiedenis en Oudheidkunde, vierde reeks, IX.

VAN DER WEE, Herman (1963): The growth of the Antwerp market and the European economy: fourteenth-sixteenth centuries, Lovaina, Bureaux du Recueil, 3 vols.

VAN DILLEN, Jan G. (1917): "Stukken betreffende den Amsterdamschen graanhandel omstreeks het jaar 1681", Economische Historische Jaarboek, III, p. 93.

VAN EEGHEN, Julius H. (1951): Inventariasen van de archieven van de Directie van de Moscovische handel. Commissarissen tot de Graanhandel, Amsterdam, Gemeentelijke Archiefdenst.

VAN KONINGSBRUGGE, Johannes Simon (1990): “A time of war: Dutch-Baltic relations in the years 1709-1711", en LEMMINK, Jacques Ph., y VAN KONINGSBRUGGE, Johannus Simon (eds.), Baltic Affairs. Relations between the Netherlands and North-eastern Europe, 1500-1800, Nijmegen, Institute for Northern and Eastern European Studies, pp. 141-159.

VRIES, Jan de, y VAN DER WOUDE, Ad (1995): Nederland 1500-1815. De eerste ronde van moderne economische groei, Amsterdam, Balans.

WEBBER, Klaus (1999): “Les livres douaniers de L'Amirauté de Hambourg au XVIIIe siècle, Une source de grande valeur encore inexploitée", Bulletin du Centre d'Histoire des Espaces Atlantiques, Serie 9, pp. 93-126.

-(2004): Deutsche Kauflete im Atlantikhandel 1680-1830, Verlag C. H. Beck Manchen. WELLING, George M. (1998): The Prize of Neutrality. Trade relations between Amsterdam and North America 1771-1817. A study in computational history, Hilversum, Verloren. 